\title{
Benefícios do uso do methimazole em comparação a hidroquinona no tratamento do
}

\section{Melasma}

\author{
Benefits of using methimazole in comparison to hydroquinone in the treatment of Melasma \\ Beneficios del uso de metimazol en comparación con hidroquinona en el tratamiento del Melasma
}

Recebido: 29/11/2021 | Revisado: 05/12/2021 | Aceito: 08/12/2021 | Publicado: 16/12/2021

Fernanda Novaes Fernandes

ORCID: https://orcid.org/0000-0002-4976-1527

Faculdade Independente do Nordeste, Brasil

E-mail: fnoovaes@gmail.com

Gisllainy Aguiar Vieira

ORCID: https://orcid.org/0000-0003-3463-8216

Faculdade Independente do Nordeste, Brasil

E-mail:gy_aguiar@hotmail.com

Jeane Rocha Santos

ORCID: https://orcid.org/0000-0002-1398-3638

Faculdade Independente do Nordeste, Brasil

E-mail: Jeane@fainor.com.br

\begin{abstract}
Resumo
As hipercromias faciais são distúrbios pigmentares causados por uma elevação da melanina em um determinado local da pele. O melasma é uma hipercromia adquirida, clinicamente diagnosticada, que apresenta grande índice de reincidência. Sua etiopatogenia ainda não é totalmente conhecida, incluindo diversos fatores que facilitam o seu aparecimento ou agravam o problema, entre eles estão a exposição a raios UV, genética, gestação, terapias hormonais, entre outros. O tratamento ainda é um desafio e por muitos anos a hidroquinona foi uma das substâncias mais utilizadas como inibidora de tirosinase, porém apresenta muitos efeitos tóxicos e nocivos para a pele e outros órgãos. Alguns tratamentos alternativos com outros despigmentantes, como o metthimazol, também de uso tópico, vem se mostrando progressivamente mais eficazes e com menos efeitos colaterais quando comparados a hidroquinona. Além disso, tratase de uma pesquisa de caráter descritivo exploratório. Serão selecionados artigos que apresentem com temática principal o melasma e que tenham sido publicados entre os anos de 2009 a 2020, serão excluídos aqueles artigos publicados antes de 2009 e que não tenham ligação com o tema. O estudo concluiu que o uso do methimazol é mais seguro e efetivo quando comparado a hidroquinona, porém possui resultados mais lentos. Ressalta-se a importância de novas pesquisas que avaliem a segurança e eficácia do uso tópico de methimazol.
\end{abstract}

Palavras-chave: Metimazol; Melasma; Hidroquinona.

\begin{abstract}
Facial hyperchromias are pigmentary disorders caused by an increase in melanin in a specific area of the skin. Melasma is an acquired hyperchromia, clinically diagnosed, with a high rate of recurrence. Its etiopathogenesis is not fully known, including several factors that facilitate its appearance or aggravate the problem, including exposure to UV rays, genetics, pregnancy, hormonal therapies, among others. Treatment is still a challenge and for many years hydroquinone was one of the most used substances as a tyrosinase inhibitor, but it has many toxic and harmful effects on the skin and other organs. Some alternative treatments with other depigmenting agents, such as metthimazole, also for topical use, have been increasingly effective and with fewer side effects when compared to hydroquinone. This is a literature review study that consists of the existence of two objectives, which are to contextualize a problem and verify existing possibilities in the literature in the formation of the theoretical framework. Furthermore, it is a descriptive exploratory research. Articles that present melasma with the main theme and that have been published between 2009 and 2020 will be selected. Those articles published before 2009 and that have no connection with the topic will be excluded. Conclusion: the study concluded that methimazole use is safer and more effective when compared to hydroquinone, but has slower results. The importance of further research evaluating the safety and efficacy of topical methimazole use is emphasized.
\end{abstract}

Keywords: Metimazole; Melasma; Hydroquinone.

\section{Resumen}

Las hipercromías faciales son trastornos pigmentarios causados por un aumento de melanina en un área específica de la piel. El melasma es una hipercromía adquirida, diagnosticada clínicamente, con una alta tasa de recurrencia. Su etiopatogenia aún no se conoce del todo, incluyendo varios factores que facilitan su aparición o agravan el problema, 
entre ellos la exposición a los rayos UV, la genética, el embarazo, las terapias hormonales, entre otros. El tratamiento sigue siendo un desafío y durante muchos años la hidroquinona fue una de las sustancias más utilizadas como inhibidor de la tirosinasa, pero tiene muchos efectos tóxicos y nocivos sobre la piel y otros órganos. Algunos tratamientos alternativos con otros agentes despigmentantes, como el metimazol, también de uso tópico, han sido cada vez más eficaces y con menos efectos secundarios en comparación con la hidroquinona Se trata de un estudio de revisión de la literatura que consiste en la existencia de dos objetivos, los cuales son contextualizar un problema y verificar las posibilidades existentes en la literatura en la formación del marco teórico. Además, se trata de una investigación exploratoria descriptiva. Se seleccionarán los artículos que presenten melasma con el tema principal y que hayan sido publicados entre 2009 y 2020. Se excluirán aquellos artículos publicados antes de 2009 y que no tengan relación con el tema. El estudio concluyó que el uso de metimazol es más seguro y más efectivo en comparación con la hidroquinona, pero tiene resultados más lentos. Se enfatiza la importancia de que se investiguen más a fondos que evalúen la seguridad y eficacia del uso tópico de metimazol.

Palavras clave: Metimazol; Melasma; Hidroquinona.

\section{Introdução}

A pele é o maior órgão do corpo humano e também o que possui mais células (Lima et al., 2018). Dentre elas destacamse os melanócitos que são células localizadas na camada basal, cuja principal função é produção da melanina, pigmento proteico que fornece proteção contra os raios UV (Nogueira \& Costa, 2019). A hiperestimulação dos melanócitos, causada por fatores intrínsecos ou extrínsecos, pode acentuar a produção de melanina, levando assim ao surgimento das hipercromias, que são regiões que assumem um aspecto mais escurecido em relação à coloração normal da pele (Gonchoroski \& Corrêa, 2005).

Conforme Souza et al (2018), a produção de melanina pelos melanócitos pode ser estimulada por questões externas ou internas, o que leva a um acúmulo de melanina dérmica, epidérmica ou ambos, originando as hipercromias. As Hipercromias faciais são consideradas distúrbios pigmentares causados por um aumento na produção de melanina no tegumento, normalmente ocorrendo a pigmentação local.

Dentre as principais hipercromias, destaca-se o melasma que é considerado uma hipercromia adquirida, facilmente diagnosticada em exame clínico, porém com grande cronicidade e reincidência frequentes (Miot et al., 2009). Apresenta bordas simétricas e é descrito por uma cor acastanhada geralmente manifestada na face na região zigomática, frontal e orbicular da boca (Souza et al., 2018). O Melasma possui etiopatogenia que não é completamente conhecida, que inclui diversos fatores que são considerados "gatilhos" em sua formação, entre elas estão a exposição aos RUV, predisposição genética, gravidez, anticoncepcionais ou outras terapias hormonais (Souza et al., 2018).

A intervenção terapêutica dessa disfunção ainda é considerada um desafio. O filtro solar é a maior das recomendações somado a agentes despigmentantes com intenção de vetar a ação da tirosinase (principal enzima responsável pela produção da melanina). Pode-se citar a hidroquinona, considerada um dos produtos mais utilizados no tratamento do Melasma ao longo dos anos, sua capacidade clareadora foi notada ainda no ano de 1936 e na década de 50 começou a ser comercializada (D’orsi, 2017). As formulações com hidroquinona podem conter substâncias tóxicas para a pele como suco de limão, resorcinol, mercúrio, potassa, entre outras, que podem colaborar com a formação de ocronose, síndrome causada pelo acúmulo de ácido nos tecidos conjuntivos (D’orsi, 2017).

Em alternativa à hidroquinona considera-se o uso de outros despigmentantes no tratamento do melasma, oferecendo menores riscos à saúde e menos efeitos adversos (Bodo et al., 2019). O Methimazole (MMI) trata-se de um medicamento anti tireóide oral que tem sido relevante nos tratamentos de hipercromias, por possuir uma ação despigmentante quando administrado topicamente (Malek et al, 2013). De acordo com Kasraee (2003), contrariamente a hidroquinona, o methimazole não causa a morte das células que produzem a melanina, os melanócitos. Além disso, não possui efeito citotóxico e nem mutagênicos (Kasraee 2008).

Neste contexto, o presente estudo apresenta como objetivo principal analisar os benefícios do methimazole em comparação à hidroquinona no tratamento do melasma. 


\section{Metodologia}

Trata-se de uma revisão integrativa de literatura, que de acordo com Alves e Mazzotti (2002), consiste na existência de dois objetivos: realizar a contextualização de um problema e averiguar as possibilidades existentes na literatura para a formação de um referencial teórico. Além disso, é uma pesquisa de caráter descritivo exploratório, já que apresenta um tema pouco explorado (Gil, 2010). Através dos descritores escolhidos foi realizada uma busca nas bases eletrônicas, tais como: a Scientific Eletronic Library Online - Scielo, Bireme, Google acadêmico, LILACS (Literatura científica e técnica da América Latina e Caribe) e BVS - Biblioteca Virtual em Saúde 20 artigos que apresentaram informações sobre o tema deste estudo, podendo ser revisão de literatura ou estudo de caso. Os artigos foram escolhidos através da leitura da revisão e da introdução dos mesmos. Sendo assim, após a análise inicial 14 artigos foram descartados por não se enquadrarem totalmente nos critérios de inclusão e exclusão adotados. Os critérios de inclusão adotados foram: artigos que apresentaram a temática em questão e que foram publicados entre os anos de 2009 a 2020. Como critérios de exclusão: não foram aceitos artigos que não tinham ligação com o tema, ou que tinham sido publicados anteriormente ao ano de 2009. Inicialmente foram selecionados 20 artigos, após análise 5 foram descartados por terem sido publicados anteriormente ao ano de 2010. Após serem criteriosamente analisados mais 9 artigos por não terem relação com a temática deste estudo. Ao final restaram 6 artigos que sem adequarem completamente aos critérios de inclusão e exclusão. Os dados obtidos foram analisados e artigos escolhidos foram organizados em um quadro subdividido em: autor, tema, objetivos, métodos, resultados e ano de publicação. Também foi feita uma análise descritiva e comparativa dos dados acumulados sobre a temática em questão, pois desta forma, a abordagem da temática ficou mais explícita e objetiva. O estudo seguiu as questões éticas dispostas na Lei de Direitos Autorais: Lei número 9,610, de fevereiro de 1998, assegurando que os materiais que foram utilizados para a realização do estudo estão referenciados de forma correta, evitando cópias e plágios.

\section{Resultados e Discussão}

Após a leitura na íntegra dos artigos pré-selecionados resumos e verificando a relevância ao tema da pesquisa, foram selecionados para o estudo 6 artigos científicos. Para facilitar a compreensão, os resultados tabulados serão apresentados no Quadro 1, contendo informações referentes ao título, autores e ano de publicação, objetivos, métodos e principais resultados de cada artigo selecionado. 
Quadro 1 - Artigos segundo título, autores e ano de publicação, objetivos, métodos e principais resultados. Vitória da Conquista,

Bahia, Brasil. 2021.

\begin{tabular}{|c|c|c|c|c|}
\hline Título & Autor $\backslash$ Ano & Objetivos & Métodos & Resultados \\
\hline 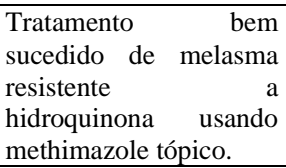 & $\begin{array}{l}\text { Malek et al. } \\
(2013)\end{array}$ & $\begin{array}{l}\text { Descrever dois casos de Melasma } \\
\text { que falharam com o uso da } \\
\text { hidroquinona, mas que responderam } \\
\text { com sucesso ao uso tópico de } \\
\text { methimazole a 5\%. }\end{array}$ & $\begin{array}{l}\text { Trata-se de um } \\
\text { estudo de caso. }\end{array}$ & $\begin{array}{l}\text { Os autores concluíram que o methimazole apresenta-se } \\
\text { como uma boa alternativa para o tratamento de pacientes } \\
\text { cujo melasma é resistente à intervenção com a } \\
\text { hidroquinona. }\end{array}$ \\
\hline $\begin{array}{l}\text { Segurança } r \text { de } \\
\text { Methimazole Tópico } \\
\text { para o Tratamento de } \\
\text { Melasma }\end{array}$ & $\begin{array}{l}\text { Kasraee et } \\
\text { al. }(2008)\end{array}$ & $\begin{array}{l}\text { Avaliar a segurança de methimazole } \\
\text { tópico usado para tratar lesões } \\
\text { pigmentadas, sem afetar hormônios } \\
\text { da tireoide. }\end{array}$ & $\begin{array}{l}\text { Trata-se de um } \\
\text { estudo de caso. }\end{array}$ & $\begin{array}{l}\text { O metimazol tópico foi bem tolerado pelos Pacientes. } \\
\text { Não apresentaram características citotóxicas e não } \\
\text { mutagênicas, indicando que este agente pode ser } \\
\text { considerado como um composto de despigmentação da } \\
\text { pele seguro para o tratamento tópico de doenças } \\
\text { hiperpigmentares da pele em humanos. }\end{array}$ \\
\hline $\begin{array}{l}\text { A eficácia e segurança } \\
\text { do metimazol } 5 \% \text { tópico } \\
\text { vs } 4 \% \text { hidroquinona no } \\
\text { tratamento do melasma: } \\
\text { um estudo randomizado } \\
\text { ensaio controlado. }\end{array}$ & $\begin{array}{l}\text { Gheisari et } \\
\text { al. (2019) }\end{array}$ & $\begin{array}{l}\text { Este ensaio teve como objetivo } \\
\text { avaliar a eficácia e segurança do } \\
\text { metimazol vs hidroquinona } 4 \% \text { que } \\
\text { é o tratamento padrão ouro no } \\
\text { manejo do melasma }\end{array}$ & $\begin{array}{l}\text { Trata-se } \\
\text { ensaio um } \\
\text { ensaplo- } \\
\text { cego. }\end{array}$ & $\begin{array}{l}\text { Ambos os grupos mostraram uma redução na pontuação } \\
\text { MASI na } 8^{\text {a }} \text { semana, que foi mais significativo no grupo } \\
\text { da hidroquinona, mas a maior taxa de recaída também foi } \\
\text { observada neste grupo após a suspensão do } \\
\text { medicamento. }\end{array}$ \\
\hline $\begin{array}{l}\text { Comparação do uso de } \\
5 \% \text { de metimazol Creme } \\
\text { com Ácido Kójico } 4 \% \\
\text { no tratamen to do } \\
\text { melasma. }\end{array}$ & $\begin{array}{l}\text { WYDYA et } \\
\text { al. (2018) }\end{array}$ & $\begin{array}{l}\text { Esta pesquisa visa avaliar a eficácia, } \\
\text { a satisfação do paciente e efeitos } \\
\text { adversos da terapia sem } \\
\text { hidroquinona com creme de } \\
\text { metimazol a } 5 \% \text { em comparação } \\
\text { aqueles que usam ácido kójico } 4 \% \\
\text { no tratamento do melasma. }\end{array}$ & $\begin{array}{l}\text { Trata-se de um } \\
\text { estudo simples- } \\
\text { cego em } 45 \\
\text { pacientes com } \\
\text { melasma. }\end{array}$ & $\begin{array}{l}\text { As diminuições na pontuação MASI e na quantidade de } \\
\text { pigmento foram maiores usando } 5 \% \text { de creme de } \\
\text { metimazol do que ácido kójico } 4 \% \text {. A satisfação do } \\
\text { paciente, quanto ao uso de } 5 \% \text { o creme de metimazol foi } \\
\text { maior do que o ácido kójico a } 4 \% \text {. Os efeitos adversos } \\
\text { foram principalmente encontrado com o uso de creme de } \\
\text { metimazol a 5\%. }\end{array}$ \\
\hline $\begin{array}{ll}\text { Ácido Kójico } & \text { no } \\
\text { Tratamento } & \text { do } \\
\text { Melasma. } & \end{array}$ & $\begin{array}{l}\text { Farag et at. } \\
(2021)\end{array}$ & $\begin{array}{l}\text { Avaliar a eficácia e segurança do } \\
\text { metimazol, aplicado durante sessões } \\
\text { de microagulhamento e uso tópico } \\
\text { adicional entre as sessões, no } \\
\text { tratamento do melasma. }\end{array}$ & $\begin{array}{l}\text { Trata-se de um } \\
\text { estudo clínico e } \\
\text { dermascópico. }\end{array}$ & $\begin{array}{l}\text { Houve significantes melhorias clínicas e } \\
\text { dermatoscópicas; as pontuações no hemi-MAIS nos } \\
\text { lados direitos tratados com metimazol foram diminuidas } \\
(p<0,001) \text {. A porcentagem de melhora no hemi-MAIS } \\
\text { foi significativamente associada com o padrão malar ( } p \\
=0,031) \text { e epidérmico tipo }(p=0,04) \text { de melasma. Cerca } \\
\text { de } 70 \text { por cento dos pacientes estudados relataram estar } \\
\text { satisfeitos com a resposta ao tratamento ( } 7 \% \text { excelente, } \\
33 \% \text { bom, } 30 \% \text { justa). Nenhum efeito colateral local ou } \\
\text { sistêmico significativo foi observado. Níveis séricos de } \\
\text { TSH pré e pós-tratamento estavam dentro da faixa } \\
\text { normal em todos os casos tratados. }\end{array}$ \\
\hline
\end{tabular}

Fonte: Dados da pesquisa.

O tratamento do Melasma requer constância e exige tempo e paciência. Na maioria das vezes pode haver muita demora até se encontrar um tratamento que seja eficiente para atingir uma resposta satisfatória (Bodo et al., 2018). Um dos recursos é o uso de agentes despigmentantes, que atuam sobre a enzima tirosinase, impedindo a formação da melanina e a transição de tirosina em DOPA, protegendo o DNA e RNA da ação dos melanotóxicos (Gonchorosk \& Correa, 2005). A despigmentação acontece de maneira gradual e os resultados satisfatórios são obtidos a longo prazo. Os agentes clareadores agem em mecanismos de ação diferentes, sendo relacionados, entre outros, com a destruição de melanócitos, inibição dos melanossomas, da biossíntese de tirosinase, da formação da melanina, degradação de melanossomas e queratinócitos (Nicoletti et al., 2002).

A droga mais utilizada para inibição da tirosinase, reduzindo a melanogênese, é a hidroquinona (Prignano et al., 2007). Porém, seu uso continuado tem efeitos colaterais como dermatite de contato alérgica ou irritativa, hiperpigmentação pós inflamatória, despigmentação permanente, ocronose, melanose conjuntival e despigmentação ungueal, além da alta chance de recidiva após cessar o uso da droga que, influenciaram a busca de novos tratamentos com diferentes princípios clareadores (Nordlund et al., 2006). Poucos estudos clínicos e o acesso descontrolado a altas concentrações por períodos prolongados tem trazido consequências que podem aumentar os seus efeitos adversos (D'orsi 2017).

Trata-se de um tratamento tópico clareador para o melasma que age inibindo a tirosinase, pois impede a conversão da Dopa em melanina (Nordlund et. al., 2006). Também irá promover, só que de forma mais lenta, a modificação estrutural nas membranas das organelas dos melanócitos, levando a destruição dos mesmos e degradação dos melanossomas, apresentando efeito citotóxico e mutagênico (Castro et. al., 1997). 
$\mathrm{Na}$ última década, novos riscos com o uso da hidroquinona foram percebidos. Entre eles a ocronose com uma descoloração azul- esbranquiçada, especialmente na população negra (U.S. Food \& Drug Administration, 2009). Outra preocupação do uso da hidroquinona se dá devido ao seu potencial risco de produção de derivado benzeno após a metabolização hepática. O composto hidroquinona desloca sua rota hepática para as vias renais para ser excretado, apresentando risco do desenvolvimento de adenoma renal devido aos metabólitos tóxicos (Maibach, 2001).

Devido a esses fatores, surge a necessidade de buscar por outros agentes despigmentantes mais seguros e eficazes como possível recurso para o clareamento (Moreira, 2010). Um dos agentes citados na literatura é o metimazol, medicamento antitireoidiano oral onde observou-se uma ação despigmentante em seu uso tópico. Testado com sucesso em humanos, a substância não alterou os níveis de hormônios tireoidianos (Malek et al., 2013). Realiza metabolização através da inibição da peroxidase que interfere diretamente na síntese de melanina, além de ser inibidor da tirosinase de cogumelo, podendo assim, teoricamente, realizar o bloqueio da hidroxilação da tirosina em DOPA nos melanócitos, importante etapa na biossíntese (Kasraee, 2002).

Em um estudo aprofundado, Kasraee et al (2004) equiparou os efeitos despigmentantes e citotóxicos de methimazole, ácido kójico, arbutin e hidroquinona, onde o Methimazol não reduziu a quantidade de melanócitos, sugerindo que seu mecanismo de ação fosse por meio da inibição da melanogênese, sem ser considerado melanocitotóxico, ao contrário da hidroquinona mesmo em baixas concentrações (Chan, 2014).

Outras vantagens do uso do methimazol foram sugeridas ao longo dos estudos, como reduzir o eritema causado por raios ultravioletas, pois se trata de um agente inodoro, com potencial proteção solar (Kasraee et al., 2004). Com isso, chegaram a confirmação de que o methimazol é um agente despigmentante seguro e eficaz, com eficácia adjuvante a outros tratamentos tópicos (Atefi, 2016), representando assim, uma alternativa para o tratamento de melasma. Apresentou-se eficaz, de acordo com estudos de Malek et al, em 2 casos de melasma resistentes a hidroquinona que alcançaram melhora clínica em 8 semanas com o uso tópico de methimazol a 5\% (Malek et al., 2013).

Por ser um medicamento utilizado em sua forma oral para tratamento da tireoide, levantou-se a preocupação de efeitos adversos relacionados a absorção sistêmica, porém, os estudos acima citados comprovam a falta de efeitos colaterais do methimazol nos índices do TSH (Malek et al., 2013). Em um estudo, Kasraee et al., relatou não haver alterações significativas em 20 pacientes com melasma tratados com a forma tópica de methimazol, relatando que a medicação tópica não possui efeitos sistêmicos.

\section{Conclusão}

Diante do exposto, conclui-se que o uso do methimazol é mais seguro e efetivo quando comparado a hidroquinona, porém possui resultados mais lentos. No entanto, é considerado um potente despigmentante, por inibir a melanogênese, sendo um agente com potencial proteção aos raios UV, tornando-se uma opção para o tratamento do melasma sem efeitos colaterais significativos.

Ressalta-se a importância de novos e aprofundados estudos acerca do tema, pois ainda apresenta uma literatura escassa. São necessários mais ensaios que avaliem a segurança e eficácia do uso tópico de methimazol. Existem limitações aos estudos, como a quantidade baixa de pacientes nos testes e curto período de tempo, além da falta de histopatologia. Também se faz necessário novos estudos acerca do tema que demonstrem as concentrações e o tempo de uso adequado do Methimazol em pacientes com melasma. 


\section{Referências}

Atefi, N., Behrangi, E., Nasiripour, S., Mehran, G., Naeji, S., Azizi, M., Hassani, P., \& Azizian, Z. (2016). A double blind randomized trial of efficacy and safety of 5\% methimazole versus 2\% hydroquinone in patients with melasma. Journal of Skin and Stem Cell, In Press(In Press). https://doi.org/10.5812/jssc.62113

Bodo, L. F. L., da Silva Rodrigues, T., \& Rabito-Melo, M. F. (2019). Eficácia e segurança de agentes despigmentantes em comparação à hidroquinona. Revista Terra \& Cultura: Cadernos de Ensino e Pesquisa, 34(esp.), 154-163. http://periodicos.unifil.br/index.php/Revistateste/article/view/1019

Castro, C. C. A., Pimenta, C. L., \& Dorane, I. (1997). Tratamento da hiperpigmentação: uva ursina versus hidroquinona. Comest Toiletries, 8(2), 39-43.

Chan, C. F., Lai, S.T., Guo, Y.C., \& Chen, M. J. (2014). Efeitos inibitórios de novos derivados de methimazole sintético em tyrosinase de cogumelo e melananogênese. Bioorgânica \& química medicinal, 22(9), 2809-2815.

Gil, A. C. (2010). Métodos e técnicas de pesquisa social (6a ed.). Atlas.

Gonchoroski, D. D., \& Corrêa, G. M. (2005). Tratamento de hipercromia pós-inflamatória com diferentes formulações clareadoras. Infarma, 17(3-4), 84-8.

Kasraee, B., Hügin, A., Tran, C., Sorg, O., \& Saurat, J.-H. (2004). Methimazole is an inhibitor of melanin synthesis in cultured B16 melanocytes. Journal of Investigative Dermatology, 122(5), 1338-1341. https://doi.org/10.1111/j.0022-202x.2004.22509.x

Kasraee, B., Safaee Ardekani, G. H., Parhizgar, A., Handjani, F., Omrani, G. R., Samani, M., Nikbakhsh, M., Tanideh, N., Eshraghian, A., Sorg, O., \& Saurat, J. H. (2008). Safety of topical methimazole for the treatment of melasma. Skin Pharmacology and Physiology, 21(6), 300-305. https://doi.org/10.1159/000148222

Levin, C. Y., \& Maibach, H. (2001). Exogenous ochronosis. American Journal of Clinical Dermatology, 2(4), 213-217. https://doi.org/10.2165/00128071200102040-00002

Lima, A. M. S., Fontes, R. L., Mello, M. Z. L. A., \& de Luna Oliveira, B. (2018). A Fotoproteção na prevenção do Câncer de Pele. Revista Saúde \& Ciência Online, 7(2), 181-183. https://rsc.revistas.ufcg.edu.br/index.php/rsc/article/view/106

Malek, J., Chedraoui, A., Nikolic, D., Barouti, N., Ghosn, S., \& Abbas, O. (2013). Tratamento bem sucedido de melasma resistente à hidroquinona usando mehimazole tópico. Terapia dermatológica, 26(1), 69-72.

MAZZOTTI, T. B. (2002). A metáfora percurso no debate sobre políticas educacionais no Brasil contemporâneo. Escola pública e sociedade. São Paulo: Saraiva, 124-132.

Metsavaht, L. d. (2017). Hydroquinone: Hero or villain? Surgical \& Cosmetic Dermatology, 9(3). https://doi.org/10.5935/scd1984-8773.20179301

Miot, L. D.B., Miot, H. A., Silva, M. G. D., \& Marques, M. E. A. (2009). Fisiopatologia do melasma. Anais brasileiros de dermatologia, 84, $623-635$.

Moreira, A. M., Bravo, B. S. F., da Fonseca Amorim, A. G., Luiz, R. R., \& Issa, M. C. A. (2010). Estudo duplo cego comparativo entre hidroquinona e extrato de uva-ursina no tratamento do melasma. Surgical \& Cosmetic Dermatology, 2(2), 99-104.

Nicoletti, M. A., Orsine, E. M. D. A., Duarte, A. C. N., \& Buono, G. A. (2002). Hipercromias: aspectos gerais e uso de despigmentantes cutâneos. Cosmetics \& Toiletries (Edição em Português), 14.

Nogueira, d. S. E., \& Costa, L. M. O. (2019). Efeitos do pycnogenol® (extrato da casca de pinus pinastes) como antioxidante e clareador - revisão de literatura. Revista Saúde em Foco, (11).

Nordlund, J. J., Grimes, P. E., \& Ortonne, J. P. (2006). A segurança da hidroquinona. Journal of the European Academy of Dermatology and Venereology, 20(7), $781-787$

Prignano, F., Ortonne, J. P., Buggiani, G., \& Lotti, T. (2007). Therapeutical approaches in melasma. Dermatologic clinics, $25(3), 337-342$.

Souza, L. C. D., Amurim, N. P., \& Grignolli, L. C. M. E. (2018). O uso associado do ácido kójico e ácido glicólico como alternativa à hidroquinona no tratamento de melasma. Revista Científica Multidisciplinar Núcleo do Conhecimento, 1(2), 49-68. 